\title{
Induced sputum examination: diagnosis of pulmonary involvement in Fabry's disease
} Margaret M Kelly, Richard Leigh, Rick McKenzie, Dennis Kamada, E Helen Ramsdale,
Frederick E Hargreave

\begin{abstract}
Fabry's disease is a rare inherited metabolic disorder caused by a deficiency in the enzyme $\alpha$-galactosidase $A$. It can affect almost every organ, including the lungs. Confirmation of lung involvement has depended on invasive bronchial biopsy specimens or brushings to confirm the presence of typical lamellar inclusion bodies within bronchial epithelial cells. We report a patient with known Fabry's disease in whom these inclusion bodies were identified by examination of induced sputum.
\end{abstract}

(Thorax 2000;55:720-721)

Keywords: Fabry's disease; induced sputum; electron microscopy

Fabry's disease is a rare $\mathrm{X}$-linked metabolic disorder in which the primary defect is an inherited deficiency of the enzyme $\alpha$-galactosidase A. ${ }^{1}$ This results in an abnormal accumulation of the glycosphingolipid ceramide trihexoside in vascular smooth muscle throughout the body, particularly in vessels of the skin, kidneys, heart, pulmonary vascular system, and neurological system. $^{2}$ Patients with lung involvement can present with varying symptoms including dyspnoea, wheeze, haemoptysis, pneumothorax, frequent respiratory infection, and airflow limitation. ${ }^{13}$ To date, the diagnosis of lung involvement in Fabry's disease has depended on the demonstration of the typical lamellar inclusion bodies within bronchial epithelial cells in bronchial biopsy specimens, brushings, or lavage fluid. ${ }^{3}$ We describe a woman with Fabry's disease in whom lung involvement was confirmed relatively non-invasively by the examination of induced sputum.

\section{Case report}

A woman aged 34 years presented with a five year history of increasing effort dyspnoea, intermittent chest tightness, wheezing, and dry cough. She was breathless on performing light housework and her symptoms were aggravated by environmental tobacco smoke. She was thought to have asthma, but treatment with inhaled fluticasone propionate $1000 \mu \mathrm{g}$ daily and inhaled salbutamol $200 \mu \mathrm{g}$ as needed for eight weeks, followed by prednisone $30 \mathrm{mg}$ daily for two weeks, were ineffective and she was referred for further evaluation.

There was no past or family history of asthma and she had never smoked. She began to have dysaesthesia in her hands and feet at the age of 11 years, and intermittent abdominal discomfort 18 months later. Tinnitus and gradual hear- ing loss developed at 18 years, and more recently she had noted intermittent abdominal pain with associated nausea, vomiting, and diarrhoea. Investigation confirmed autonomic nervous system involvement, peripheral neuropathy, mild diastolic dysfunction, and mild proteinuria. A clinical diagnosis of Fabry's disease was confirmed by deficient plasma $\alpha$-galactosidase levels at the age of 27. Subsequent testing confirmed that one sibling and her twin sons also had the condition. She had been treated with carbamazepine and phenytoin for the peripheral neuropathy, and omeprazole and metoclopramide for abdominal pain.

On examination she was obese with a weight of $104 \mathrm{~kg}$ and height $162 \mathrm{~cm}$. Breath sounds were decreased and there was a diffuse expiratory wheeze on auscultation. Abdominal tenderness was present on palpation and there was evidence of a sensory peripheral neuropathy involving predominantly her lower limbs. Cardiovascular and skin examination were normal.

Her chest radiograph was normal. Spirometric values, lung volumes, and carbon monoxide transfer factor (TLCO) showed moderate but not significantly reversible airflow limitation, a moderate non-obstructive defect, and normal gas transfer coefficient (KCO). Her forced expiratory volume in one second $\left(\mathrm{FEV}_{1}\right)$ and slow vital capacity (VC) were 1.71 and 2.71 , improving after salbutamol to 1.91 and $3.0 \mathrm{l}$, respectively (predicted 3.31 and 3.91 ). A stage 1 exercise test showed a reduced power output ( $45 \%$ predicted) with increased ventilation at all work loads, normal heart rate response, and no oxygen desaturation or post-exercise bronchoconstriction. Allergy skin prick tests with 19 allergen extracts were negative.

Sputum was induced, selected from the expectorate, and processed with dithiothreitol as described by Pizzichini et al. ${ }^{4}$ It was mucoid, squamous cell contamination was $<5 \%$, and the cell viability was $84 \%$. The total cell count and proportion of neutrophils were raised $\left(16.4 \times 10^{6}\right.$ cells $/ \mathrm{mg}$ and $82.5 \%$ : normal $<9.7 \times 10^{6}$ cells $/ \mathrm{ml}$ and $\left.<64.4 \%\right),{ }^{5}$ eosinophils were borderline increased $(2.2 \%$ : normal $<1.1 \%$ ), macrophages were $14.8 \%$ (normal $<86.1 \%$ ), and lymphocytes were $0.5 \%$ (normal $<2.6 \%$ ). The sputum cell suspension was centrifuged at $290 \mathrm{~g}$ for four minutes, the cell pellet fixed in $2 \%$ glutaraldehyde in $0.1 \mathrm{M}$ cacodylate buffer at $4^{\circ} \mathrm{C}$ for two hours, and then post-fixed in cold $1 \%$ osmium tetroxide in cacodylate buffer. After dehydration in ethanol, the pellet was embedded in Spurr's epoxy resin. Ultrathin sections were stained and examined with a Philips 300 electron microscope, confirming 
A

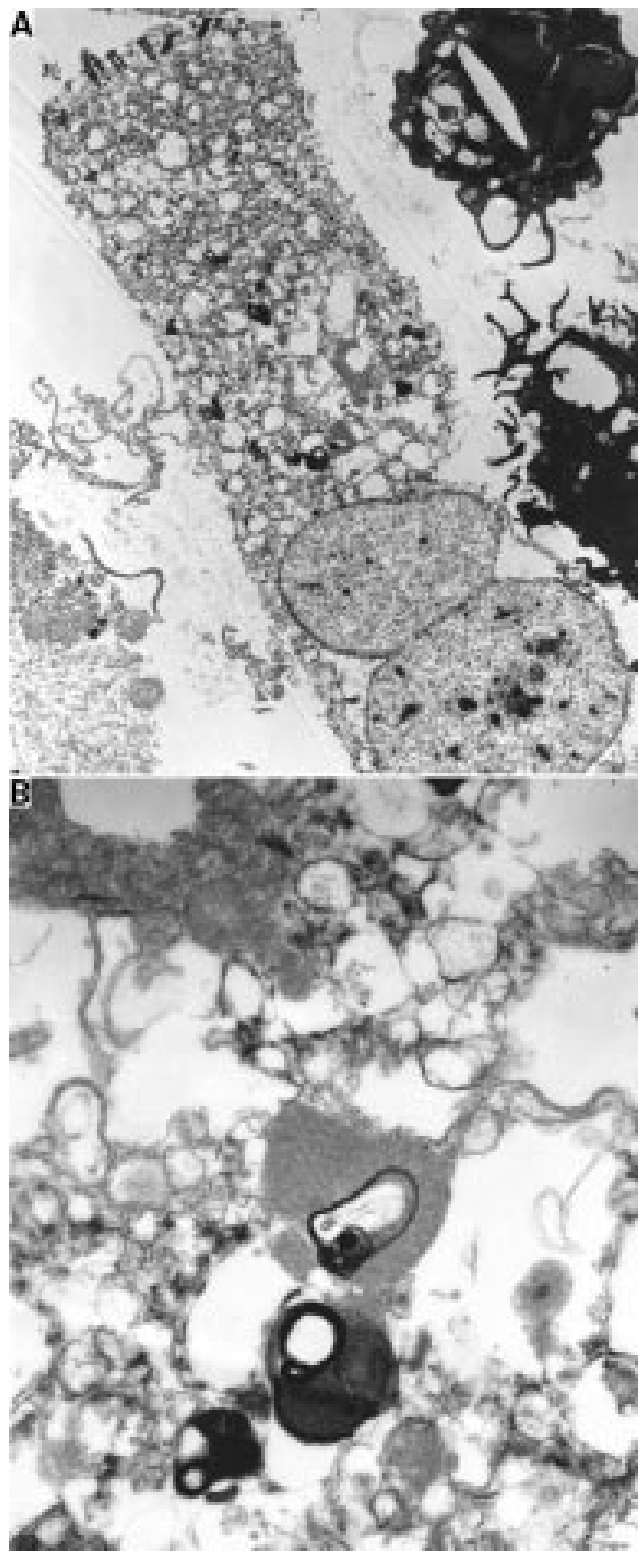

Figure 1 (A) Electron micrograph of a ciliated bronchial epithelial cell from sputum showing the accumulation within the cytoplasm of the typical laminar inclusion bodies seen in Fabry's disease. Original magnification $\times 8000$. (B) High magnification view of the intracytoplasmic lamellar bodies seen in $(A)$. Original magnification $\times 62500$.

the presence of lamellar inclusion bodies typical of Fabry's disease within all ciliated bronchial epithelial cells examined (fig 1). These inclusion bodies were not present in macrophages and were therefore not consistent with surfactant bodies. Sputum culture was negative for common respiratory pathogens.

\section{Discussion}

This report shows that lung involvement in Fabry's disease can be demonstrated by examination of induced sputum and is associated with a sterile neutrophilic inflammatory response. Presumably the source of these abnormalities is the airways since the lamellar inclusions were observed in airway epithelial cells and have previously been demonstrated in bronchial biopsy specimens and brushings. ${ }^{13}$
In addition, the inflammatory response was associated with mild to moderate chronic airflow limitation, which is a common functional abnormality in Fabry's disease ${ }^{13}$ and, in this patient, was not associated with any other cause. We have examined sputum from five subjects without Fabry's disease and were unable to find similar inclusions. The pathogenic significance of these inclusions is uncertain, and it is unknown whether they are present in patients with Fabry's disease without clinical manifestations of pulmonary involvement.

This report adds to the increasing evidence that examination of induced sputum is clinically useful. Sputum induction itself can be very successful and safe when performed by experienced technologists. ${ }^{6}$ The processing of the sputum for cell counts and some fluid phase measurements can be reliable, valid, and responsive-the qualities of good measurements. Induced sputum examination was introduced to diagnose pulmonary infection and bronchial carcinoma. More recently it has identified the occurrence of eosinophilic bronchitis without asthma and has been used to support the diagnosis of occupational asthma and poor compliance with steroid treatment. There is increasing evidence in patients who present with chronic cough, asthma, or chronic airflow limitation that sputum eosinophilia predicts a beneficial effect of steroid treatment and that the lack of sputum eosinophilia predicts a lack of response, at least to short term treatment. ${ }^{6}$ Recent studies also raise the possibility that the presence of haemosiderin in macrophages in sputum might be used as the surrogate marker of heart failure in breathless patients $^{8}$ and that the presence of lipidcontaining macrophages correlates with reflux to the level of the upper oesophageal sphincter. ${ }^{9}$ Consideration therefore needs to be given to making available reliable sputum examination for indications other than just the diagnosis of lower respiratory infection.

The authors would like to thank Sharon Weston for performing the sputum cell counts. Richard Leigh is a South African Pulmonology Society Boehringer-Ingelheim Fellow.

1 Brown LK, Miller A, Bhuptani A, et al. Pulmonary involvement in Fabry's disease. Am $\mathcal{F}$ Respir Crit Care Med 1997;155:1004-10.

2 Peters FP, Sommer A, Vermeulen A, et al. Fabry's's disease: a multidisciplinary disorder. Postgrad Med $\mathcal{F}$ 1997;73:7102 .

3 Rosenberg DM, Ferrans VJ, Fulmer JD, et al. Chronic Rosenberg DM, Ferrans VJ, Fulmer JD, et al. Chronic
airflow obstruction in Fabry's's disease. Am $\mathcal{f}$ Med airflow obstruction

4 Pizzichini E, Pizzichini MM, Efthimiadis A, et al. Indices of airway inflammation in induced sputum: reproducibility and validity of cell and fluid-phase measurements. $A m \mathcal{F}$ Respir Crit Care Med 1996;154:308-17.

5 Belda J, Leigh R, Parameswaran K, et al. Induced sputum cell counts in healthy adults. Am $\mathcal{F}$ Respir Crit Care Med 2000;161:475-8.

6 Hargreave FE. Induced sputum for the investigation of airway inflammation: evidence for its clinical application. Can Respir f 1999;6:169-74.

7 Parameswaran K, Leigh R, Hargreave FE. Sputum eosinophil count to assess compliance with corticosteroid therapy in asthma. F Allergy Clin Immunol 1999;104:502-3.

8 Leigh R, Sharon RF, Efthimiadis A, et al. Diagnosis of leftventricular dysfunction from induced sputum examination. Lancet 1999;354:833-4.

9 Parameswaran K, Efthimiadis A, Allen CJ, et al. Lipid-laden macrophages in induced sputum: a marker of acid aspiration in gastro-esophageal reflux. Am $\mathcal{f}$ Respir Crit Care Med 1999;159:A514. 